\title{
27. Mapping a waste disposal site using Tellus airborne geophysical data
}

\author{
Ulrich Ofterdinger, ${ }^{\mathrm{I}}$ C. Wilson, ${ }^{2}$ Martin Robinson, ${ }^{\mathrm{I}}$ \\ Jean-Christophe Comte, ${ }^{3}$ Rachel Cassidy, ${ }^{4}$ David \\ Beamish $^{5}$ and Alastair Ruffell ${ }^{\mathrm{I}}$
}

How to cite this chapter:

Ofterdinger, U., Wilson, C., Robinson, M., Comte, J.-C., Cassidy, R., Beamish, D. and Ruffell, A., 2016 'Mapping a waste disposal site using Tellus airborne geophysical data' in M.E. Young (ed.), Unearthed: impacts of the Tellus surveys of the north of Ireland. Dublin.

Royal Irish Academy.

DOI:10.3318/

978-1-908996-88-6.ch27
Leakage of fluids from unregulated and/or poorly engineered waste disposal sites poses a significant direct risk to groundwater quality. Characterisation and monitoring of waste disposal sites and potentially associated groundwater contaminant plumes are generally invasive, time-consuming and expensive, particularly when the extent of the plume is unknown. This study examines the value of incorporating of Tellus and Tellus Border airborne electromagnetic (AEM) data into current assessment protocols for the characterisation and monitoring of contaminant sources and subsurface contaminant plumes. The findings demonstrate the feasibility of using airborne and ground-based non-invasive geophysical data as part of existing tiered assessment protocols for prioritising suspected sites and for guiding targeted intrusive investigations and subsequent remediation efforts.

\section{BACKGROUND}

Under the European Union Water Framework Directive, Member States are required to assess water quality across national and transboundary surface water and groundwater bodies. Work completed to date has identified numerous national transboundary surface water and groundwater bodies across the island of Ireland as 'at risk'. Point source pollution, such as that associated with pollutant plumes emanating from land contamination, including unregulated waste disposal sites, was recorded as one of the key contributors in the deterioration of water quality. Unregulated cross-border movement and disposal of waste (Department of Justice, 2010) as well as historic, poorly engineered, permitted disposal sites have led to a legacy of environmental impacts to water bodies across the island of Ireland that pose technical and financial challenges. As part of a Code of Practice

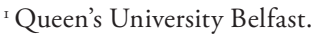

${ }^{2}$ University of Ulster, Belfast.

${ }^{3}$ University of Aberdeen.

${ }^{4}$ Agri-Food and Biosciences Institute, Belfast.

s British Geological Survey, Keyworth.
} 


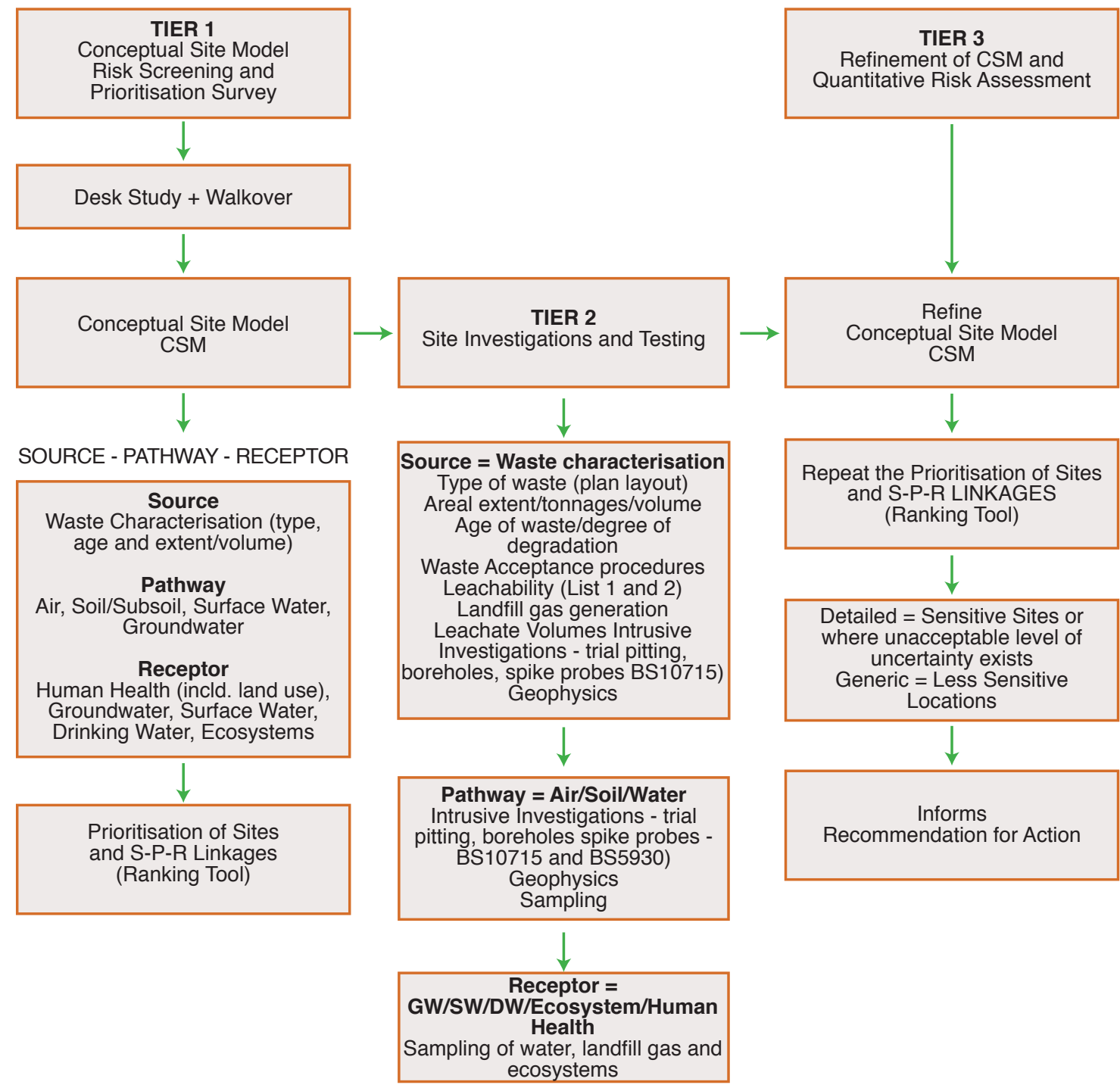

(CoP), the Environmental Protection Agency (EPA) provides guidance on completing environmental risk assessments of unregulated waste disposal sites (EPA, 2007). SNIFFER (2008) and the NIEA (2009) provide details regarding the initial classification and assessment process for identifying and prioritising landfill sites that pose a particular risk to the water environment. Figure 27.1 illustrates a phased approach to the evaluation of a site based on investigating potential source-pathway-receptor linkages as risk drivers.

The characterisation and monitoring of waste disposal sites are generally invasive, time-consuming and expensive. In particular, adequately capturing potential groundwater contaminant plumes emanating from disposal sites with monitoring installations such as boreholes, when the extent of the feature is unknown and the presence of contamination

Figure 27.1. Conceptual model of risk assessment methodology for waste disposal sites (EPA, 2007). 


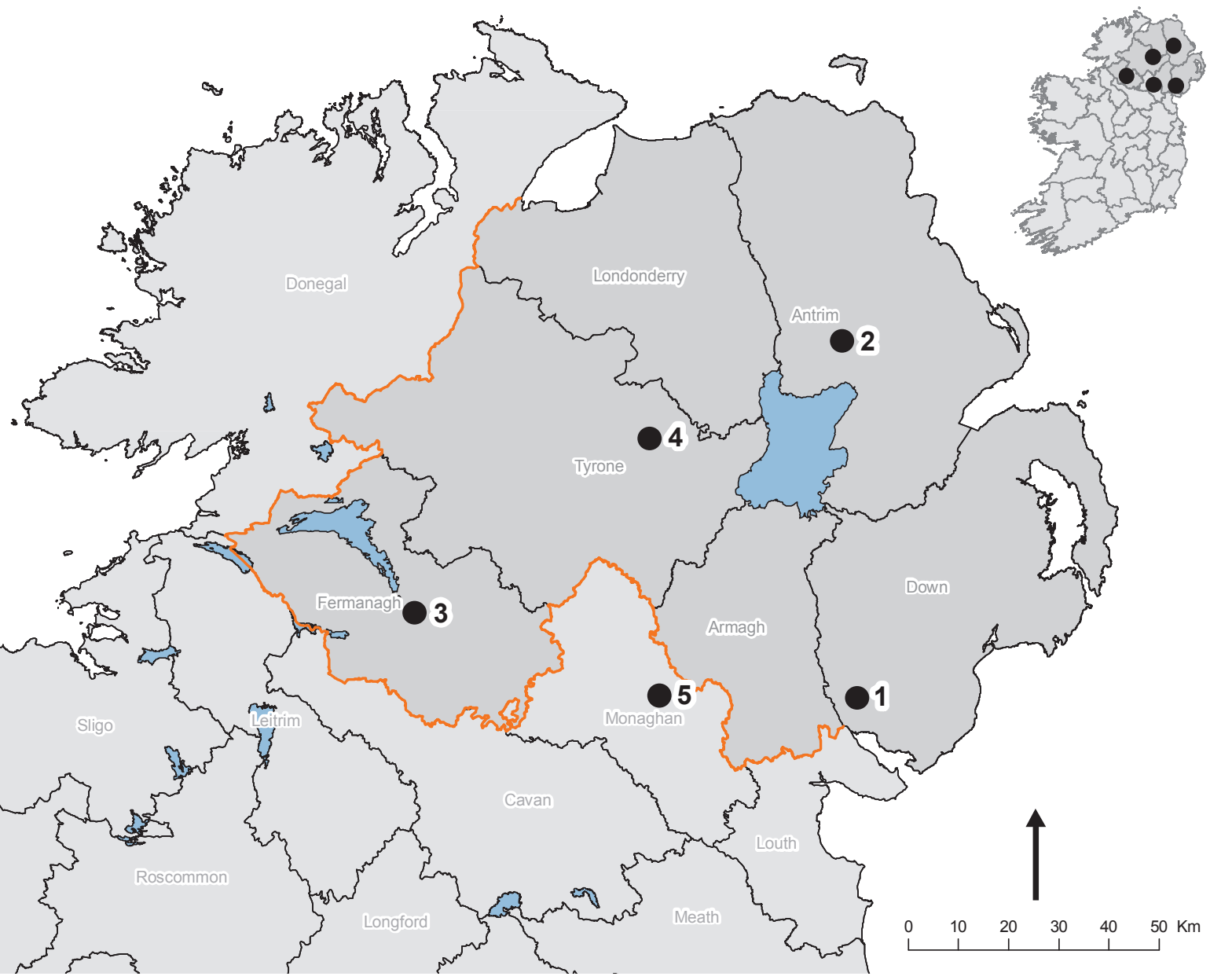

Figure 27.2. Location of case study sites. is evident only from indirect observations, can be prohibitively expensive. Constraints related to the location of monitoring installations can result in an incomplete assessment of environmental contamination. A borehole network, for example, may not provide sufficient coverage of an area affected by pollution, resulting in uncertainty in relation to the pollution source and pathways.

Airborne geophysical survey data provide an opportunity for the rapid and costeffective spatial assessment of potential pollution plumes, as previously demonstrated by Beamish $(2003,2005,2007)$. This study explores the potential for using the Tellus AEM survey data to assess the nature and extent of suspected contaminant sources and associated subsurface contaminant plumes at selected case study sites in Northern Ireland and the Republic of Ireland. The details of the airborne surveys have been described by Beamish et al. (2006); Hodgson and Ture (2013); and Hodgson and Young (Chapter 2, this volume).

This study aims at facilitating a combined approach to the characterisation and monitoring of pollution sources adversely affecting water bodies, as well as improving the targeting of costly intrusive monitoring and restoration efforts. The study has been designed to complement existing risk assessment strategies, with the results of the project indicating how the analysis of airborne geophysical data may be incorporated into the framework of existing assessment protocols. 


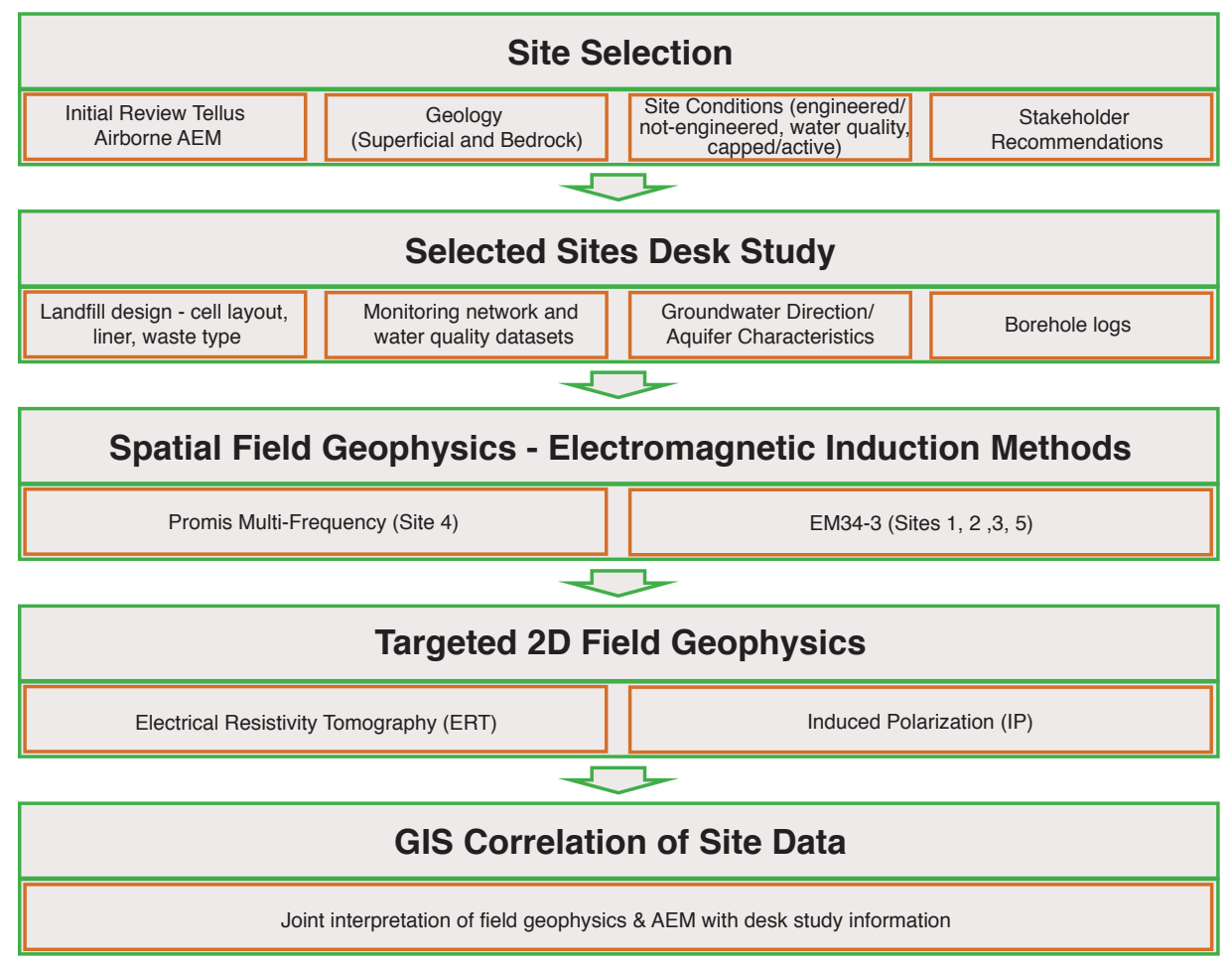

\section{Methodology}

Case study investigations

The study selected five landfill sites with existing groundwater monitoring data and other existing site information to investigate the use of AEM data for assessing potential subsurface contaminant impact. Sites were selected according to factors such as varying geology (drift and bedrock), water quality, the degree of site engineering and availability of existing geological and groundwater monitoring data. These case studies (Fig. 27.2) were examined to determine the feasibility of characterising the disposal site and potential associated groundwater contaminant plumes by airborne geophysics over a range of environmental settings. Ground-based geophysical surveys were completed at these sites to investigate to what extent the monitoring of disposal sites and subsurface pollutant plumes could benefit from the integration of AEM data with ground-based geophysical data. Figure 27.3 summarises the workflow completed at the case study sites.

The methodology was developed following a targeted approach. The AEM data for each of the selected sites were assessed to aid targeting of the field surveys. Both the raw, point data and interpolated raster grids for low-frequency $(3 \mathrm{kHz})$ and high-frequency $(12 / 14$ $\mathrm{kHz}$, dependent on survey block) were compared with the mapped landfill boundaries and expected groundwater flow direction, to identify areas in which the AEM data appeared to 
Bedrock unit zonal statistics

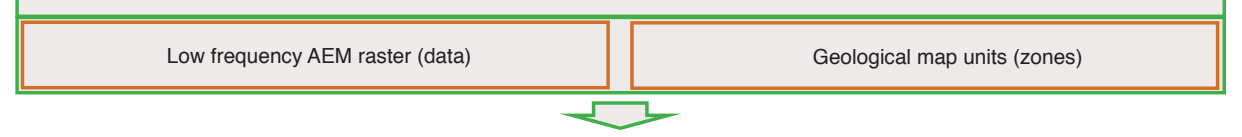

Mean conductivity classification for each geological unit

प

Low frequency AEM raster (data) minus mean conductivity map

एᄂ

Normalised AEM map

ए

Landfill database (site boundary, age volume, additional information if available)

Zonal statistics of normalised AEM map using landfill site boundary as zone

$\sqrt{2}$

Mean (bedrock normalised) conductivity for each landfill

Plots of landfill conductivity against landfill age and waste volume

Figure 27.4. Summary of workflow: regional study. show elevated values beyond the known landfill boundary. These areas were then targeted during the field campaigns. Information from the desk studies also delineated areas of interest at each of the sites, which were then investigated using field electromagnetic (EM) methods to delineate conductive zones surrounding the site. Subsequently, surface electrical resistivity tomography (ERT) surveys enabled high-resolution $2 \mathrm{D}$ depth profiling of conductive zones highlighted by the airborne and field-based EM methods. Two field EM methods were employed, the PROMIS multi-frequency system (IRIS Instruments) and the EM34-3 system (Geonics Ltd). The ERT surveys were conducted using a SYSCAL-Pro 72 (IRIS Instruments). ERT data were processed and inverted via Prosys and Res2Dinv software. Topography was included in the model inversion, with a refined half space model used to reduce surface effects in the modelling.

Regional study

Figure 27.4 presents an illustration of the workflow completed as part of the regional study. In an effort to assess landfills' properties in a comparable manner across the Tellus and Tellus Border AEM data sets, the background bulk conductivity, which on a regional scale is dominated by the bedrock geology, was removed. Beamish (2013) developed and undertook a geostatistical assessment of the Northern Ireland $3 \mathrm{kHz}$ AEM survey, creating a baseline classification of 56 lithological units mapped by the 1:250,000 bedrock 


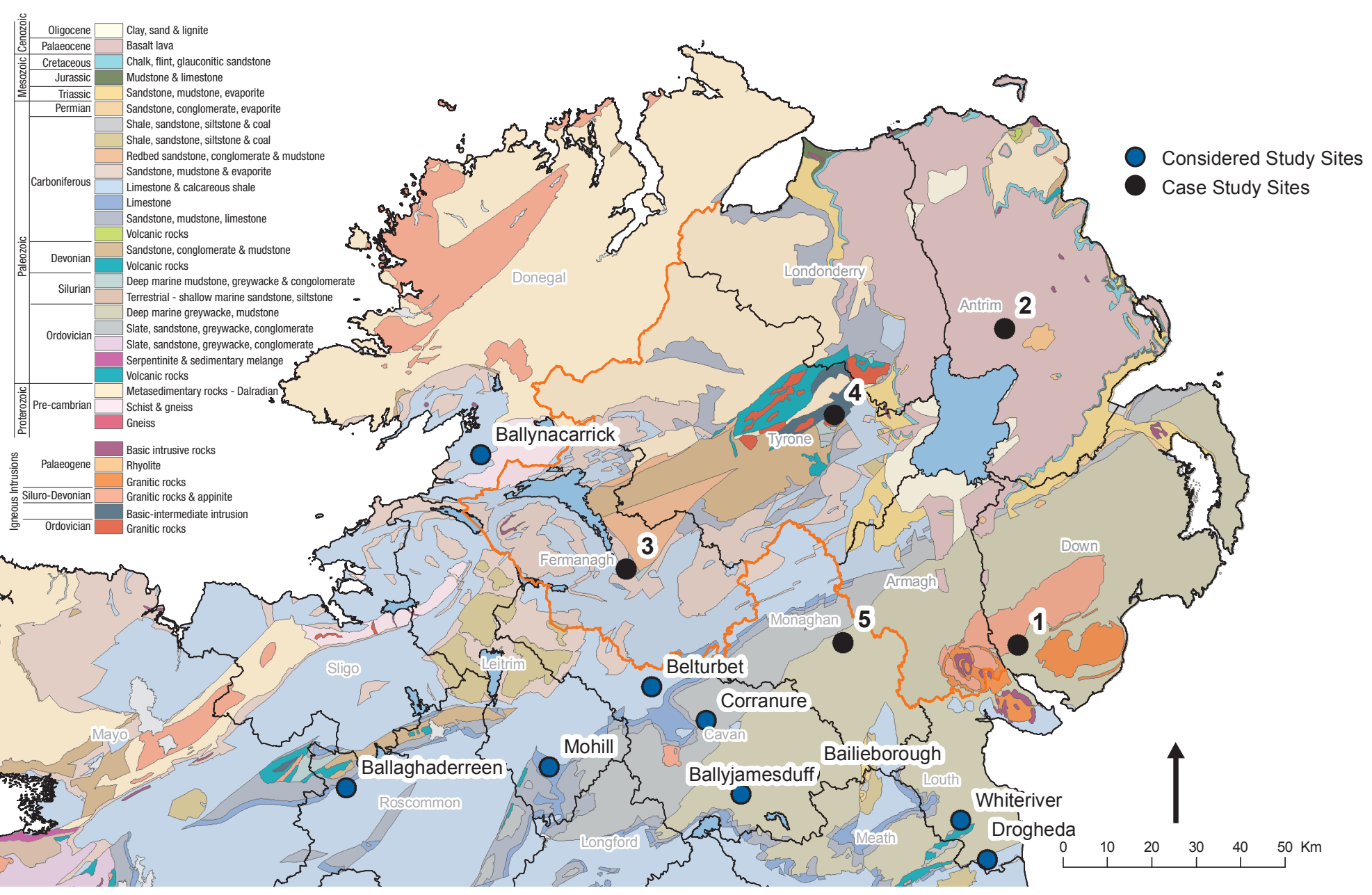

geological map of Northern Ireland (GSNI, 2012). The approach applied in this study also uses this method in an attempt to remove the baseline geological conductivity from the AEM anomalies observed across selected landfills across the study area. This allows comparability between landfill anomalies and is less dependent on background geological conductivity and more representative of landfill characteristics.

For Northern Ireland the background geological conductivity values for four of the study sites were readily available from Beamish (2013). However, specific information on other landfills was not easily accessible. In the Republic of Ireland limited information, including annual environmental reports, on licensed landfills was available via the EPA Waste Licensing and Permitting Portal (EPA, 2013) but information on bedrock conductivity was not available. Using the method of Beamish (2013), an assessment of the Tellus Border AEM in conjunction with GSI $100 \mathrm{k}$ bedrock map enabled background conductivity values to be calculated in a similar approach. The approach also used the $3 \mathrm{kHz}$ electromagnetic data, with the resulting baseline raster subtracted from the total $3 \mathrm{KHz}$ conductivity raster to give a theoretical geologically corrected raster of conductivity values.

From landfill site reports in the study area, a database of landfills within this area containing attribute data was created. Attributes collated included age and the volume of waste for each of the landfill sites. Figure 27.5 shows the locations of the landfills studied.

Figure 27.5. Locations of selected case study sites (black) and other sites considered (blue) on a bedrock 1:1 million bedrock geology background. 

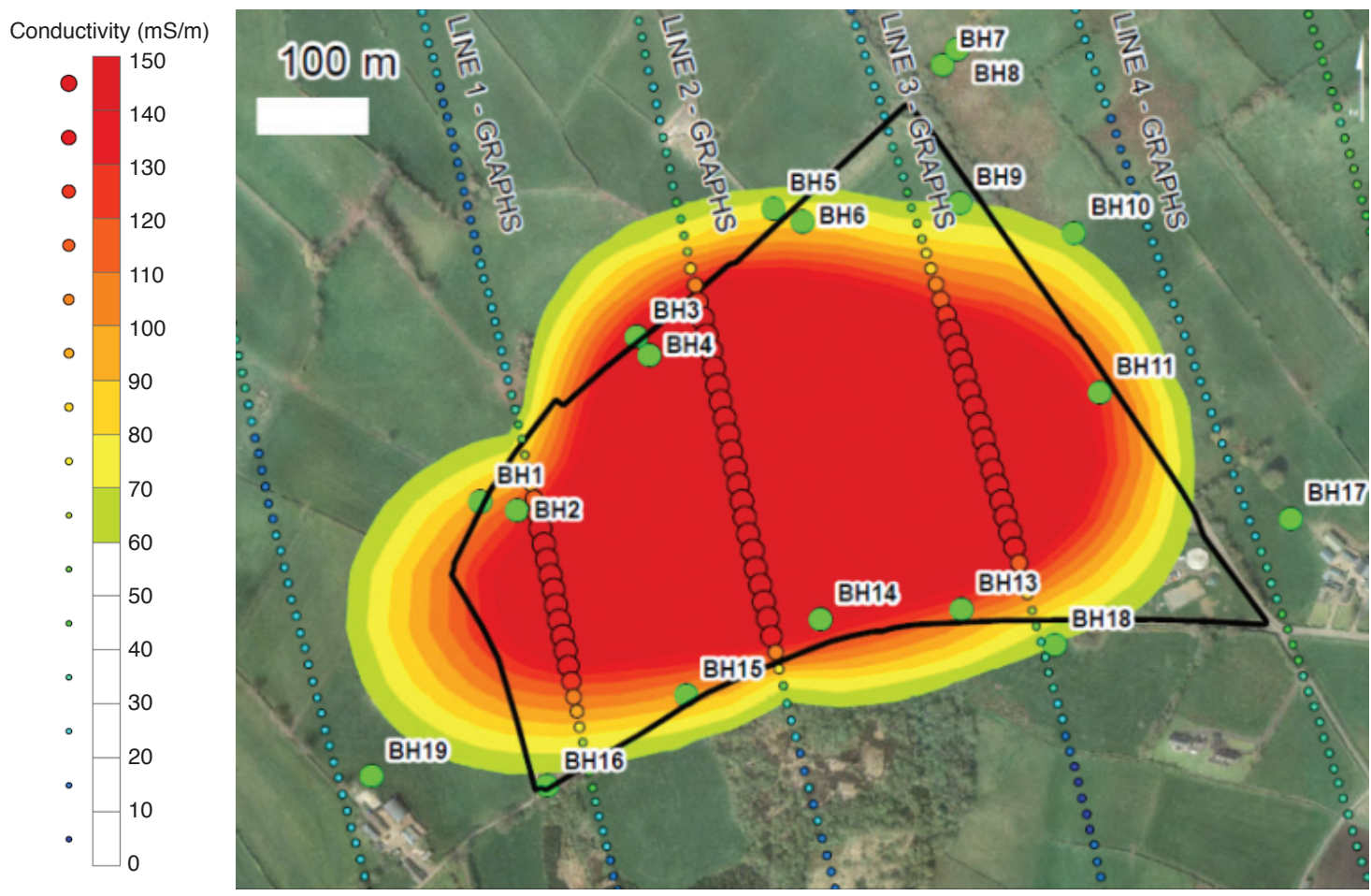

Figure 27.6. Site 2: Tellus AEM $12 \mathrm{kHz}$ apparent conductivity, flight line point data and borehole locations.
An average conductivity value for each of the landfills was then extracted based on the digitised site boundary and compared with the landfill attributes.

\section{Results}

\section{Case study investigations}

A detailed presentation of the results from across all the case study sites, covering varying geological and environmental settings, is beyond the scope of this chapter so the following highlights key findings for the case study Site 2 (Fig. 27.2). The site occupies an area of approximately 20 hectares and is located on an excavated peat moss site. The site was not constructed as an engineered containment landfill but rather operated as a 'dilute and attenuate' facility between 1963 and 2007. During this period, accepted waste included domestic and commercial wastes. Following the closure of the site a low-permeability cap was installed across the site. The regional bedrock geology consists of the Lower Basalt Formation, underlying post-glacial blanket bog and glacial till of varying thickness $(<3 \mathrm{~m}$ to $15 \mathrm{~m}$ ) and alluvial deposits. Borehole observations describe the basalt bedrock as highly weathered in the top 2-4 m. Several groundwater monitoring wells are located along the perimeter of the site (Fig. 27.6). Available monitoring data indicate a general northward groundwater flow direction and consistently elevated concentrations of leachate indicator 
4 Freq Tellus EM - Line 2

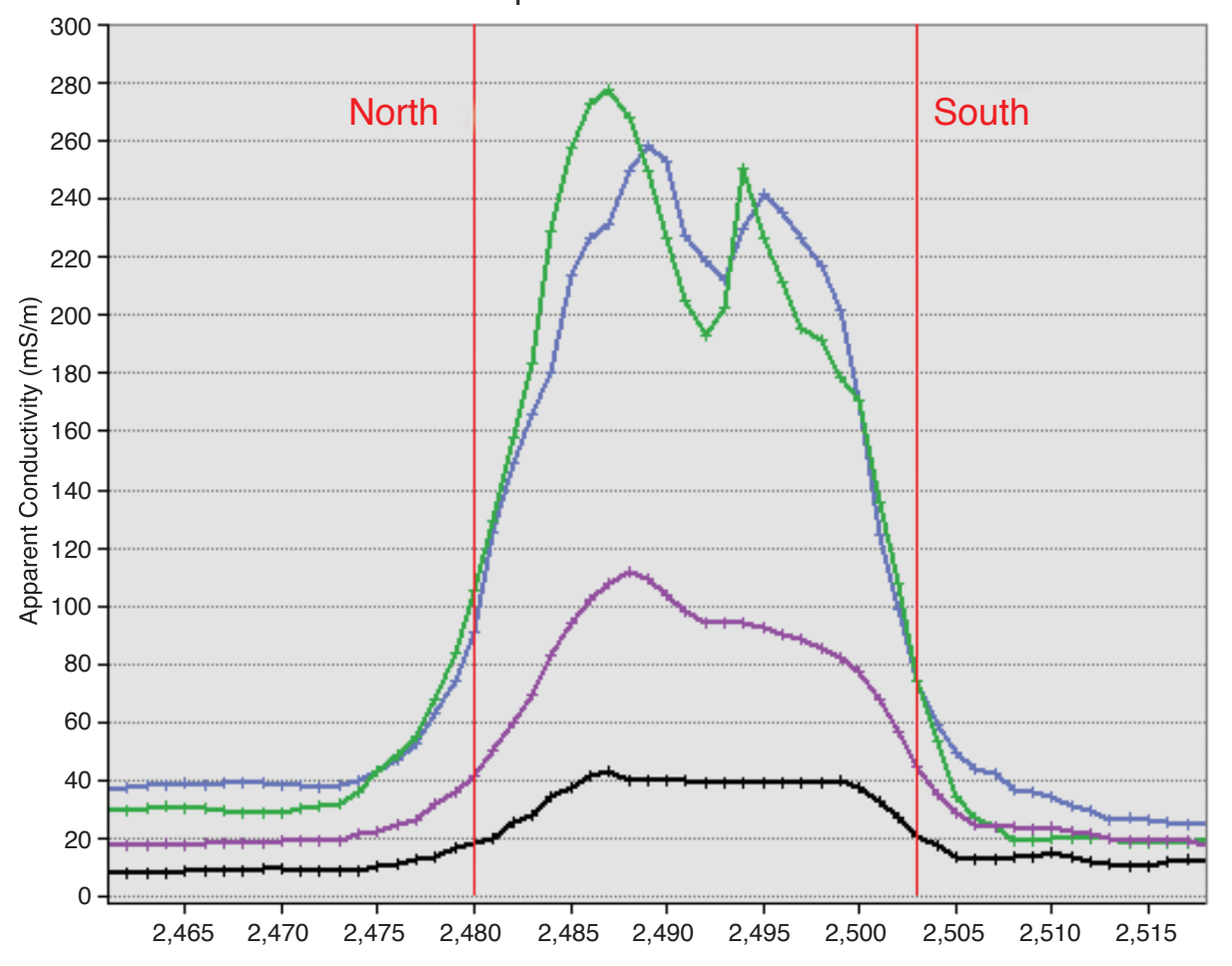

compounds at monitoring wells along the northern and north-western perimeter of the site, highlighting the potential for off-site groundwater impact in this area.

Figures 27.6 and 27.7 show the AEM apparent conductivity data in plan and crosssectional view, respectively, for Site 2 . Apparent conductivity is the conductivity calculated according to a simple planar model. The 'depth of penetration' depends on the local electrical and spatial characteristics but most of the response comes from within $60 \mathrm{~m}$ of the ground surface. The elevated conductivity values seen within the landfill boundary are as would be expected with the deposition of organic material and landfill materials. The frequency response for each of the four available EM frequencies is illustrated in Fig. 27.7 for flight line 2 . The highest apparent conductivity values occur in the two higher frequency data sets (12 and $25 \mathrm{kHz}$ ). These have a shallower depth of investigation similar to that of the buried waste, whereas the lower frequencies penetrate to greater depth. (Responses at the lower frequencies incorporate response of the deeper bedrock, which is likely to be more resistant and to dilute the landfill signal.) Areas of interest are delineated where the conductivity appears to extend outside the landfill boundary, possibly indicating dispersion of high-conductivity leachate which may pose a potential risk to groundwater. However, this must be approached with caution as, although the Tellus survey is high resolution at a regional scale, at site scale this equates, for example, to 75 data points within the landfill boundary for Site 2. Although the resolution is high along the flight line (approximately

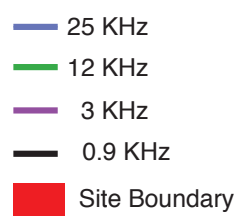

Figure 27.7. Site 2: airborne flight line \#2 data (for location see Fig. 27.6) showing AEM apparent conductivity (four frequencies) versus distance along flight line (shown as fiducial intervals of approximately $15 \mathrm{~m}$ ). 


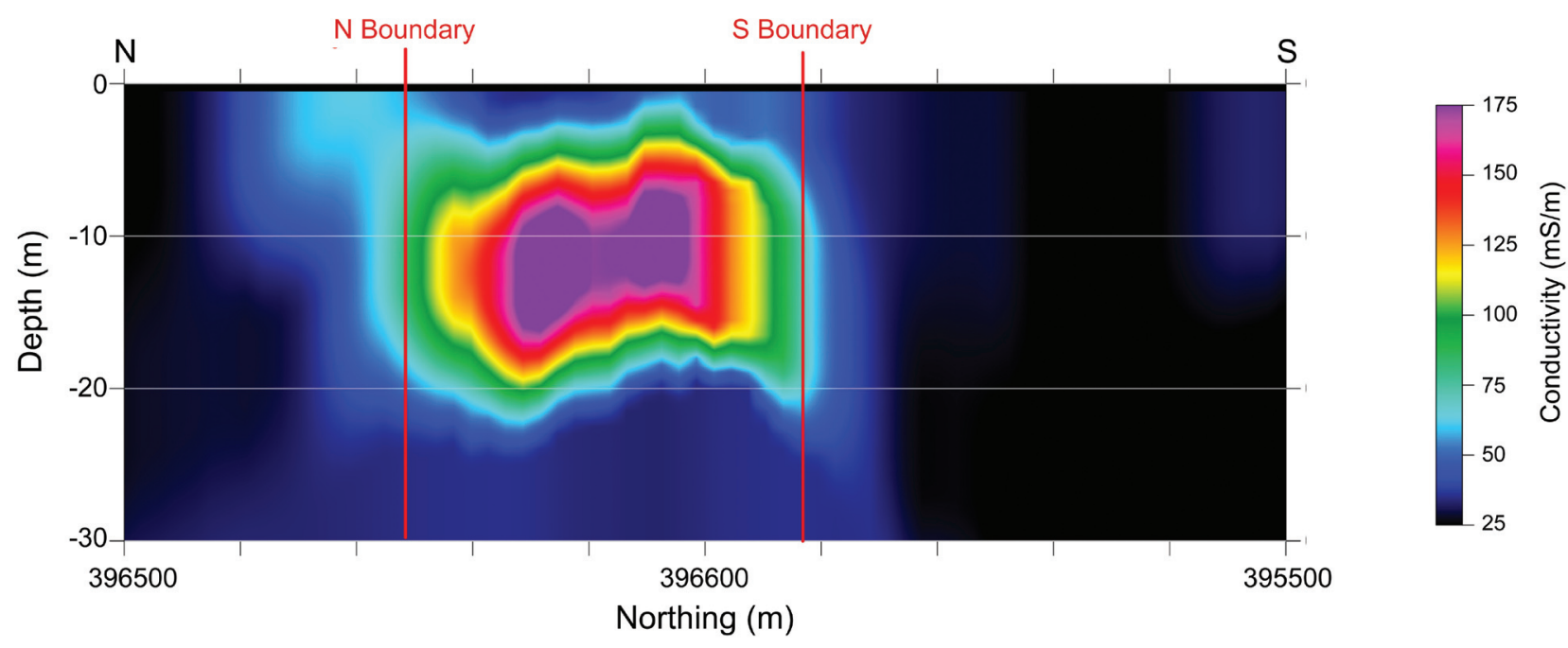

Figure 27.8. Site 2, flight line \#2: AEM conductivity inversion.
$15 \mathrm{~m}$ between samples), flight lines are spaced $200 \mathrm{~m}$ apart, which leave large areas in between unmapped. Consequently, the interpolated images, as apparent in the contouring in Fig. 27.6, can result in an anomalous extension of the high-conductivity values beyond the limits of the landfill boundary, rather than representing a real feature.

Additional information was obtained from the AEM data by numerical inversion of Line 2 (Fig. 27.8). The inversion provides good delineation of the landfill anomaly with respect to depth, which can be further compared with the field ERT results below. In this instance the inversion provides limited information with regard to the lateral extension of leachate associated with the site but provides a method to depth-characterise the site and associated leachate plume that can be further used to aid decision-making on site-scale investigation or monitoring infrastructure.

From the assessment of groundwater flow directions based on available hydrogeological data, it was decided that the main area for further field investigations would focus to the north-west of the landfill site boundary in the region between flight lines (highlighted in Fig. 27.6) with additional surveying along the other boundaries of the landfill also. Access to the northern perimeter of the site and the south-east corner was restricted.

Figure 27.9 presents results from the field EM34-3 survey at Site 2. In Fig. 27.9 a distinct change is observable when moving from the capped waste body onto the areas surrounding the site, with a sharp transition from higher conductivity to lower conductivity. This demonstrates the ability of the ground EM system to delineate the boundary of the site reasonably well. Delineating areas of potential off-site leachate migration, however, proved more difficult for the studied sites, with only subtle changes occurring in the areas surrounding the site. The area of slightly elevated conductivities extending across the north-west of the landfill boundary, surrounding $\mathrm{BH}$ 1, appeared suitable for further 


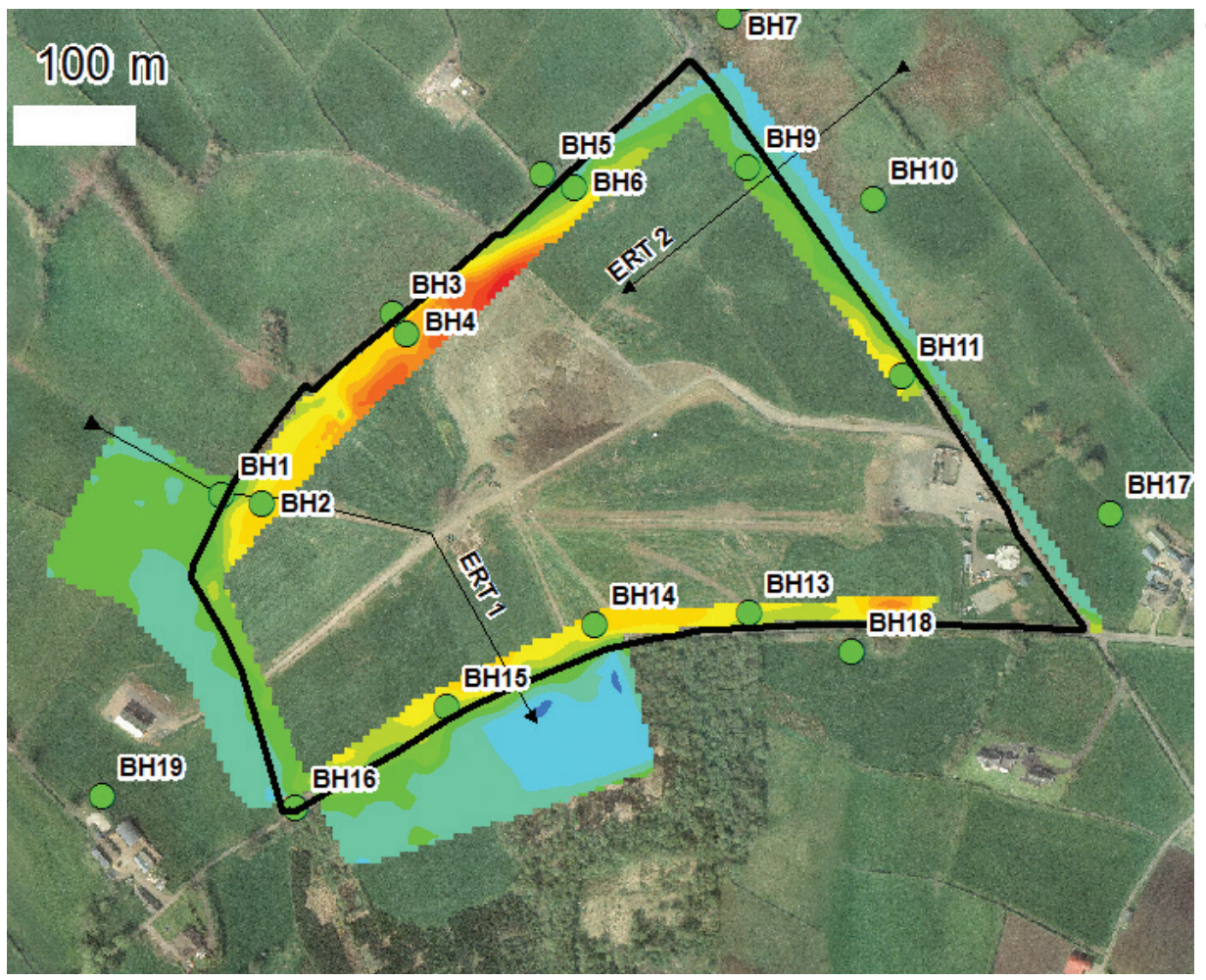

investigation with ERT profiling. In addition $\mathrm{BH} 1$ was flagged as a groundwater monitoring point during the desk study, with consistently elevated values of key leachate indicators noted. The survey area was limited along the northern boundary of the site due to access restrictions. This area along the boundary between $\mathrm{BH} 1,3$ and 5 would otherwise have been another primary target area for further field investigations.

Figure 27.10 presents an example of the ERT data (displayed as conductivity) collected along profile ERT 1 at Site 2. The advantage of ERT surveying is evident in the profiles: providing very high depth resolution and thus enabling a more accurate investigation into the dispersion of the AEM signal, landfill structure, and areas of possible leachate migration. The interpretation illustrated in Fig. 27.10 combines information from a number of sources including $\mathrm{BH}$ logs and site investigation reports in order to delineate the physical structures within the profile. Elevated conductivity values are measured below the inferred depth-to-bedrock as constrained by available borehole logs, interpreted as the possible effect of leachate modification of bedrock conductivity. An area of elevated conductivity is also apparent at $120 \mathrm{~m}$ along the profile, which would not normally be expected within the low-conductivity bedrock. It is possible that this may be a result of leachate migration from the landfill.

In summary, the AEM data provide a clear identification of the waste body within the known perimeter of the site. Elevated AEM conductivities are observed along the
Conductivity $(\mathrm{mS} / \mathrm{m})$

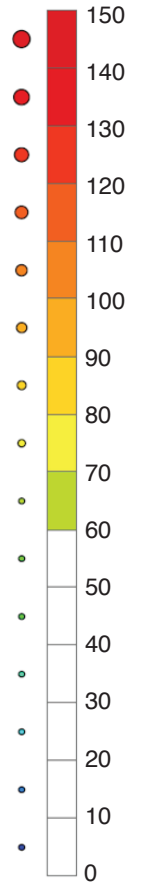

Figure 27.9. Site 2: EM34-3 horizontal dipole conductivity contours $\left(\mathrm{mS} \mathrm{m}^{-1}\right)$. Colour interval: $10 \mathrm{mS} \mathrm{m}^{-1}$. Also shown: site boundary, boreholes, and locations of ERT profiles. 


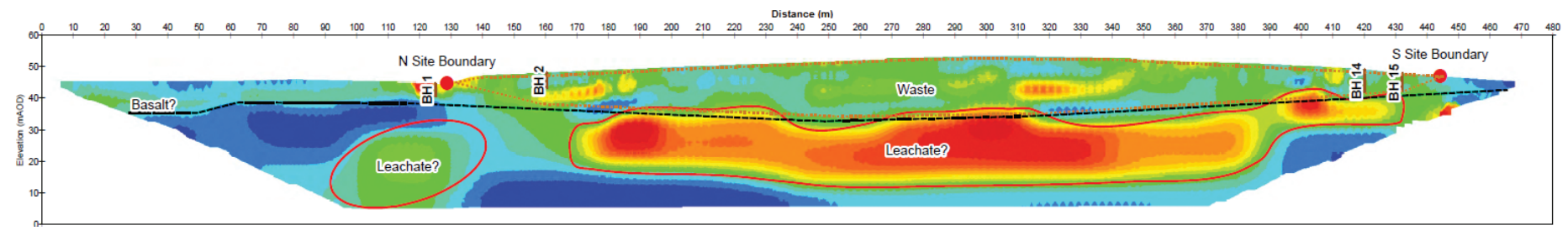

\section{ERT Interpretation}

- Site Boundary

$\mathrm{BH}$

Basalt

Leachate?

Waste Body?

Figure 27.10. Site 2: ERT 1 electrical conductivity crosssection (for location see

Fig. 27.9). Colour interval: $10 \mathrm{mS} \mathrm{m}^{-1}$.

\section{Conductivity $(\mathrm{mS} / \mathrm{m})$}

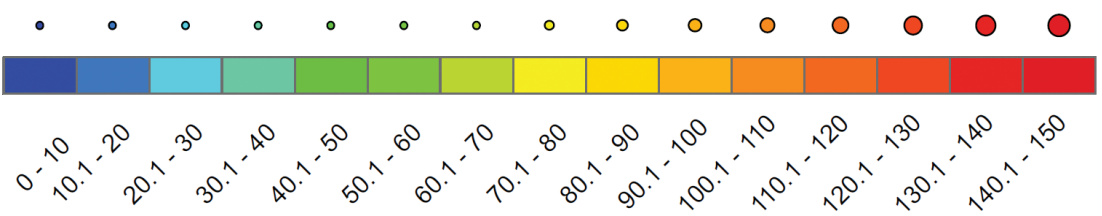

northern and north-western boundary of the site, where elevated levels of leachate indicators have been observed repeatedly at individual groundwater monitoring wells. Due to access restrictions it was not possible to confirm conclusively the veracity or lateral extent of elevated AEM data beyond the northern perimeter of the landfill site through fieldbased surveys. Along the north-western boundary, AEM observations were supplemented with field-based EM and ERT surveys. The field-based EM depicts clearly the change in conductivity between the known landfill boundary and adjacent land (where accessible). Beyond the site boundary only subtle changes in field EM data are observed. The ERT surveys completed at the site indicate potential downward leachate migration into the bedrock beneath the waste body and the potential presence of leachate at depth beneath the north-western boundary of the site. The inversion of the AEM data at this site provides a good depth resolution and may indicate the potential downward migration of leachate beneath the waste body into the underlying bedrock, similar to the observations made on the basis of the completed ERT surveys.

\section{Regional study}

Figure 27.11 presents the graphs of the residual conductivity at each landfill against the individual landfill attributes, namely approximate age (A), approximate waste volume (B) and a normalised product of waste volume and age $(\mathrm{C})$ which combines their relative influence. Four of the nine additional landfills identified in the Tellus Border region have been removed from the plots: Drogheda, Mohill, Bailieborough and Belturbet. Drogheda landfill has been removed due to uncertainty in location, and the other three because the landfills lie between flight lines.

The plots of age and volume versus the residual conductivity (Fig. 27.11) show strong positive correlations, indicating a general increase in conductivity with age of landfill and with volume of waste. (As would be expected, there is a strong positive correlation between landfill age and landfill waste volume.) The relationship of the residual waste conductivity 
Ofterdinger $e t a l$.
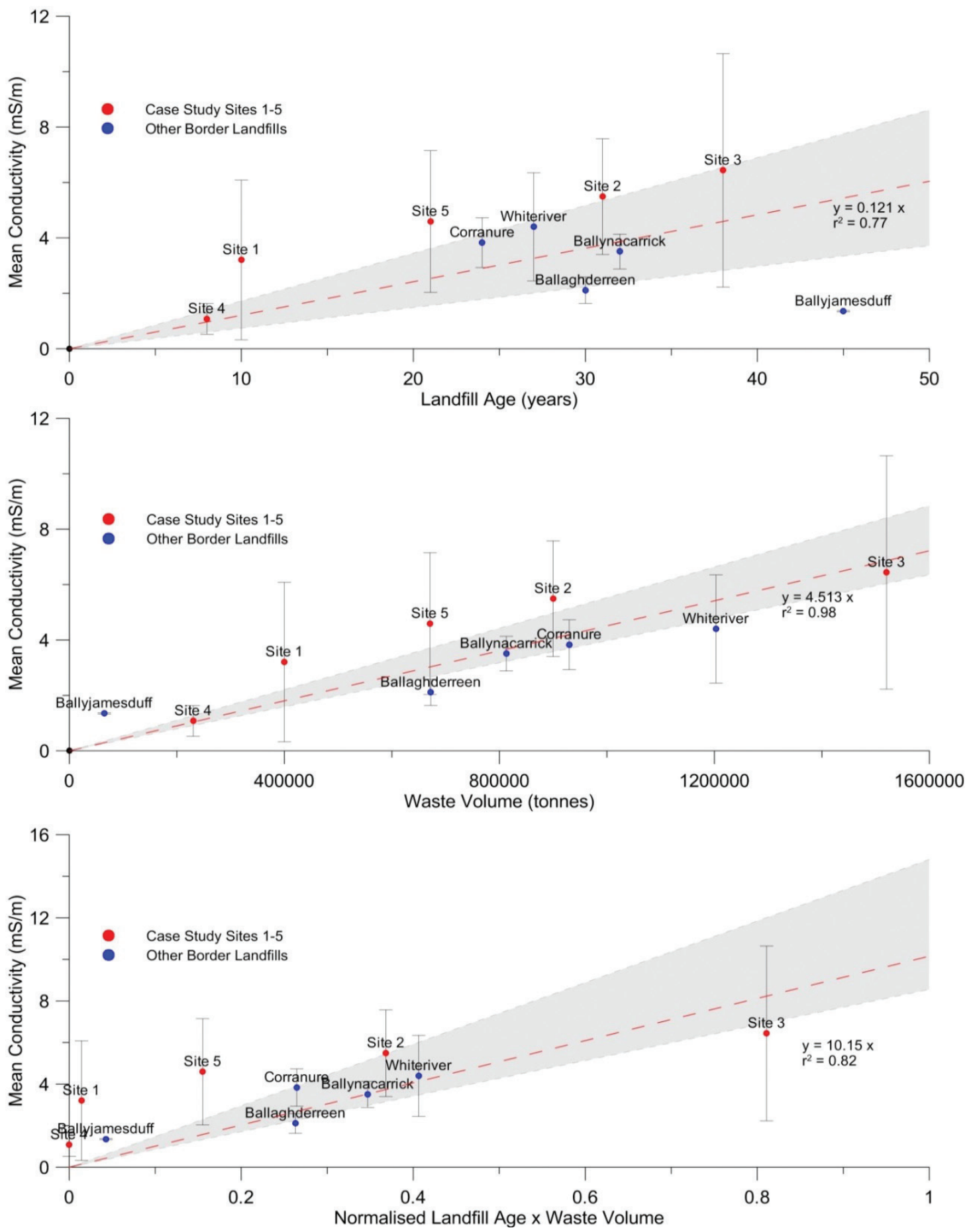
Figure 27.11. Plots of residual mean conductivity versus: (A) approximate landfill age from opening until AEM survey date; (B) approximate waste volume total contained within the landfill at the time of AEM survey; (C) normalised product of landfill age and waste volume. Error bars represent the standard deviation of the average residual conductivity; line of best fit forced through origin with $\mathrm{r} 2$, linear formula, and 95\% confidence limit also displayed. to background conductivity has also been tested and shows no strong evidence that the background conductivity still affects relationship plots in Fig. 27.11.

The positive correlations of landfill age and waste volume with residual conductivity could be due to a number of factors, which may work in combination: (1) increase in physical waste volume; (2) increased volume of leachate generated as a result of increased waste volume and rainfall infiltration; (3) changing chemistry of leachate with age; (4) less welldeveloped leachate management infrastructure in older landfills; (5) composition of waste in older landfills as opposed to newer facilities which have become more strictly regulated; and (6) addition of clay capping material (high conductivity) over old landfills which may also cover larger areas.

Although the plots in Fig. 27.11 show a positive correlation with age and volume, which might be predicted in the early stages of a landfill, it might also be expected that at some point the bulk conductivity of a landfill would begin to decrease. This is based on the concept that the overall conductivity of a landfill may be dominated by the stage of waste degradation as indicated by leachate chemistry. Meju (2000), Table 4, has reported the decrease in leachate conductivity with age. The BOD5/COD ratio has been used to estimate the state of the leachate with the ratio of young leachate between 0.4 and 0.5 (Kurniawan et al., 2006; Umar et al., 2010). The stage of waste degradation of a landfill in itself has its own list of factors that are site-specific (e.g. Umar et al., 2010; Meju, 2000). This could be significant in the risk assessment process as leachate may be regarded as the main environmental hazard in the context of landfills. The example presented demonstrates the use of AEM and ground geophysics in assessing landfill characteristics. The method may be further developed as a predictive tool for the assessment of suspected unregulated disposal sites or as a prioritisation tool for known sites.

\section{Conclusions}

To assess the feasibility of using airborne electromagnetic data for mapping the extent of pollution plumes emanating from landfills, we assessed the Tellus results over five sites, selected to reflect different environmental settings.

We compiled existing information and monitoring data to investigate the nature of potential groundwater contaminant impact at the case study sites and to validate the geophysical results. AEM data were analysed with regard to their capability for identifying the source of potential contamination (i.e. the waste body) and potential associated leachate plumes. To cross-validate the AEM interpretation, ground-based EM and electrical profiling (ERT) field surveys were made. The combined geophysical data sets were interpreted in the context of observed contaminant impact as documented at individual sites.

At all sites the AEM method demonstrated its potential for detecting waste deposits, with clear lateral changes in electrical conductivity across the site boundaries. With regard to assessing the detailed lateral extent of contaminant plumes, the AEM data are unlikely to be able to provide the resolution necessary to resolve such plumes at site-specific scales. 


\section{Ofterdinger $e$ al .}

However, the data are useful for initial identification and for prioritising target areas for more detailed investigations.

We found that background-corrected apparent conductivity correlated reasonably well with age and waste volume and demonstrated the potential of AEM as a means of assessing undocumented landfill sites or as a risk prioritisation tool for known sites. Using normalised AEM data allows the approach to be applied across different geological settings.

Within the context of existing risk assessment protocols for unregulated landfill sites, for example the EPA (2007) Code of Practice (CoP), AEM data may help in assessing the significance of suspected unregulated landfill sites, with regard to both their spatial extent and their attributes. Specifically, AEM may provide a useful additional tool for initial site prioritisation as part of Tier 1 of the CoP. In view of the transition between Tier 1 and Tier 2 elements of the CoP, AEM provides valuable information for focusing site-specific geophysical investigations, such as ground-based EM and ERT. The project highlighted the benefits and increased understanding of site-specific conditions derived from a combined application of AEM and ground-based EM and ERT data. Within the context of the progressive tiered approach of the $\mathrm{CoP}$, these non-intrusive geophysical data sets provide relevant detailed information for the subsequent design of efficient intrusive investigations and monitoring infrastructure, where required.

\section{ACKNOWLEDGEMENTS}

DB publishes with the permission of the Executive Director of the British Geological Survey (NERC).

\section{REFERENCES}

Beamish, D., 2003 'Characterising landfills from the air', First Break, 21, 10, 67-72. Available at http://nora.nerc.ac.uk/510613/.

Beamish, D., 2005 'An airborne EM survey of a landfill that leaked', First Break, 23, 55-60. Available at http://nora.nerc.ac.uk/15810/.

Beamish, D., 2007 Studies of the Geophysical Responses of Landfills in Northern Ireland Using the Tellus Airborne EM Data. Open Report IR/07/013. Keyworth, UK. British Geological Survey. Available at http://nora.nerc.ac.uk/7547/.

Beamish, D., 2013 'The bedrock electrical conductivity structure of Northern Ireland', Geophysical Journal International, 194, 683-99. Available at http://nora.nerc.ac.uk/502882/. http://dx.doi.org/10.1093/gji/ggt073.

Beamish, D., Cuss, R.J., Lahti, M., Scheib, C. and Tartaras, E., 2006 The Tellus Airborne Geophysical Survey of Northern Ireland: Final Processing Report. Keyworth, UK. British Geological Survey.

Department of Justice (NI) and Department of Justice and Law Reform (RoI), 2010 Cross-Border Organised Crime Assessment 2010. Belfast and Dublin.

Environmental Protection Agency, 2007 Code of Practice: Environmental Risk Assessment for Unregulated Waste Disposal Sites. Wexford. Environmental Protection Agency.

Environmental Protection Agency. Waste Licence Search. 2013 [Online] Available at http://www.epa.ie/licensing/waste/search. 
Geological Survey of Ireland (GSI), 2006. Bedrock Geological Map of Ireland. 1:500,000. Dublin. Geological Survey of Ireland.

GSNI, 2012. 1:250,000 Bedrock Geology. Belfast. Geological Survey of Northern Ireland.

Hodgson, J.A. and Ture, M.D., 2013 Tellus Border Project: Airborne Geophysics Data Processing Report. Dublin. Geological Survey of Ireland. Available at http://www.tellusborder.eu/Library.htm.

Kurniawan, T.A., Lo, W.H. and Chan, G.Y., 2006 'Physico-chemical treatments for removal of recalcitrant contaminants from landfill leachate', Journal of Hazardous Materials, 129, 1-3, 80-100.

Meju, M., 2000 'Geoelectrical investigation of old/abandoned, covered landfill sites in urban areas: model development with a genetic diagnosis approach', Journal of Applied Geophysics, 44, 115-50.

Northern Ireland Environment Agency (NIEA), 2009 River Basin Management Plans - Groundwater Classification, Landfill. Lisburn. Northern Ireland Environment Agency.

SNIFFER, 2008 Prioritisation of Closed Landfill Sites for Environmental Monitoring, Final Report, Project UKLQ10. Edinburgh. Available at http://www.sniffer.org.uk/index.php/ download_file/577/.

Umar, M., Aziz, H.A. and Yusoff, M.S., 2010 'Variability of parameters involved in leachate pollution index and determination of LPI from four landfills in Malaysia', International Journal of Chemical Engineering. http://dx.doi:10.1155/2010/747953. 
Unearthed: impacts of the Tellus surveys of the north of Ireland

First published in 2016 by the

Royal Irish Academy

19 Dawson Street

Dublin 2

www.ria.ie

Copyright (C) 2016 Royal Irish Academy

ISBN: 978-1-908996-88-6

The articles in this book are open access and distributed under the terms of the Creative Commons Attribution 4.0 licence, which permits unrestricted use, distribution and reproduction in any medium, provided the original authors and source are credited. To view a copy of this licence, visit https://creativecommons.org/licenses/by/4.0/

Except where noted:

Geological mapping for Northern Ireland / Tellus data are provided by the Geological Survey of Northern Ireland.

Geological mapping for Ireland / Tellus Border data are provided by the Geological Survey of Ireland.

Topographic mapping for Northern Ireland is derived from Land and Propery Services Open Data and contains public sector information licensed under the Open Government Licence v3.0. (http://www.nationalarchives.gov.uk/doc/open-governmentlicence/version/3/).

Topographic mapping for Ireland is derived from Ordnance Survey of Ireland Open Data (https://creativecommons.org/licenses/by/4.0/legalcode).

While every effort has been made to contact and obtain permission from holders of copyright, if any involuntary infringement of copyright has occurred, sincere apologies are offered, and the owner of such copyright is requested to contact the publisher.

British Library Cataloguing-in-Publication Data. A catalogue record is available from the British Library.

Design: Alex Donald, Geological Survey of Northern Ireland.

Index: Brendan O'Brien.

Printed in Poland by L\&C Printing Group. 


\section{Table of Contents:}

\section{Prelim}

DOI: https://doi.org/10.7486/DRI.b851k323d

\section{Chapter 1}

The Tellus geosciences surveys of the north of Ireland: context, delivery and impacts

DOI: https://doi.org/10.7486/DRI.st74s528d

\section{Chapter 2}

The Tellus airborne geophysical surveys and results DOI: https://doi.org/10.7486/DRI.t148tx96z

\section{Chapter 3}

The Tellus geochemical surveys, results and applications

DOI: https://doi.org/10.7486/DRI.t722wq645

\section{Chapter 4}

Stakeholder engagement for regional geoscientific surveying: the Tellus Border communications campaign

DOI: https://doi.org/10.7486/DRI.w089fr763

\section{Chapter 5}

Mineral resources and Tellus: the essential balance DOI: https://doi.org/10.7486/DRI.wd37kb12s

\section{Chapter 6}

Gold exploration in the north of Ireland: new targets from the Tellus Projects

DOI: https://doi.org/10.7486/DRI.wh24m696v

\section{Chapter 7}

Using soil geochemistry to investigate gold and base metal distribution and dispersal in the glaciated north of Ireland

DOI: https://doi.org/10.7486/DRI.wm11n3806

\section{Chapter 8}

Critical metals for hightechnology applications: mineral exploration potential in the north of Ireland DOI: https://doi.org/10.7486/DRI.wp98p0649

\section{Chapter 9}

A natural laboratory for critical metals investigations in the Mourne Mountains granites

DOI: https://doi.org/10.7486/DRI.cc08ww45f

\section{Chapter 10}

Geothermal potential of granitic rocks of the Mourne Mountains

DOI: https://doi.org/10.7486/DRI.ff36jm09f

\section{Chapter 11}

Shape and intrusion history of the Late Caledonian

Newry Igneous Complex, Northern Ireland

DOI: https://doi.org/10.7486/DRI.2v248822m

\section{Chapter 12}

Using Tellus data to enhance targeting of volcanogenic massive sulphide mineralisation in the Tyrone Igneous Complex

DOI: https://doi.org/10.7486/DRI.5x226w262

\section{Chapter 13}

The geological significance of electrical conductivity anomalies of the Ordovician- Silurian Moffat Shale Group, Northern Ireland

DOI: https://doi.org/10.7486/DRI.6m31f4149

\section{Chapter 14}

Faults, intrusions and flood basalts: the Cenozoic structure of the north of Ireland

DOI: https://doi.org/10.7486/DRI.90205h306

\section{Chapter 15}

Information for agriculture from regional geochemical surveys: the example of soil $\mathrm{pH}$ in the Tellus and Tellus Border data

DOI: https://doi.org/10.7486/DRI.dv14c8060

\section{Chapter 16}

An ecohydrological investigation of wetlands in the border counties of Ireland: a framework for a holistic understanding of wetland systems DOI: https://doi.org/10.7486/DRI.hd775d90j 
Chapter 17

Assessing nutrient enrichment risk to groundwaterdependent ecosystems in the border counties of Ireland DOI: https://doi.org/10.7486/DRI.k356pk18j

\section{Chapter 18}

Mapping the terrestrial gamma radiation dose

DOI: https://doi.org/10.7486/DRI.k930rb86z

\section{Chapter 19}

Soils and their radiometric characteristics

DOI: https://doi.org/10.7486/DRI.mp495t62g

\section{Chapter 20}

Modelling in-house radon potential using Tellus data and geology to supplement inhouse radon measurements

DOI: https://doi.org/10.7486/DRI.ns06hm86z

\section{Chapter 21}

Determining geochemical threshold values from the Tellus data sets: the examples of zinc and iodine| DOI: https://doi.org/10.7486/DRI.r2087418g

\section{Chapter 22}

Identification of the geochemical signatures of diffuse pollution in the Tellus Border soil data set, using source apportionment

DOI: https://doi.org/10.7486/DRI.wh24m698d

\section{Chapter 23}

Stream sediment background concentrations in mineralised catchments in Northern Ireland: assessment of 'pressures' on water bodies in fulfilment of Water Framework Directive objectives DOI: https://doi.org/10.7486/DRI.x633tf86g

\section{Chapter 24}

Mapping metallic contamination of soils in the Lower Foyle catchment

DOI: https://doi.org/10.7486/DRI.9k42bv355

\section{Chapter 25}

Refining the human health risk assessment process in Northern Ireland through the use of oral bioaccessibility data

DOI: https://doi.org/10.7486/DRI.9p29cr199

\section{Chapter 26}

Combining environmental and medical data sets to explore potential associations between environmental factors and health: policy implications for human health risk assessments

DOI: https://doi.org/10.7486/DRI.9s16dn03n

\section{Chapter 27}

Mapping a waste disposal site using Tellus airborne geophysical data

DOI: https://doi.org/10.7486/DRI.9w03fh87q

\section{Chapter 28}

The use of aero-magnetics to enhance a numerical groundwater model of the Lagan Valley aquifer, Northern Ireland

DOI: https://doi.org/10.7486/DRI.9z90gd711

\section{Chapter 29}

Carbon sequestration in the soils of Northern Ireland: potential based on mineralogical controls DOI: https://doi.org/10.7486/DRI.b277h9556

\section{Chapter 30}

Spatial distribution of soil geochemistry in geoforensics DOI: https://doi.org/10.7486/DRI.b564j6392

\section{End matter}

DOI: https://doi.org/10.7486/DRI.bc38m007j 